\title{
THE VIRTUAL LIBRARY FOR BLIND AND PRINT DISABLED CANADIAN STUDENTS \\ by \\ Rosemary Kavanagh
}

\begin{abstract}
As the Information Age progresses in technological and electronic areas, so must librarians re-define traditional services for those both with and without sight. Libraries are expected to participate in setting new and better service standards for those with visual disabilities and/or learning disorders. The Canadian National Institute for the Blind (CNIB) Library's national network (VISUNET : CANADA) supports the premise of a virtual library for print disabled Canadians. Information resources, services, and international collaborations such as the Digital Audio Based Information System (DAISY) are producing accessible materials for those who cannot read print. By interconnecting world information resources in any format of choice, and providing the best in content that is both digital and virtual with no limitations, libraries will assist print disabled Canadians to better compete for jobs in a rapidly changing working and learning environment.
\end{abstract}

Last year Canada was awarded the prestigious Franklin D. Roosevelt International Disability Award amongst the discordance of activists who felt the government's performance was more promise than substance. Discordance is part of every progressive façade, reflecting that Canada has balanced some inequities but has not overcome all of them. One area where inequities remain for print disabled Canadians lies in library services. Only about $3 \%$ of the trade books and $0.5 \%$ of magazines published annually are accessible, and most are produced in very limited quantities.

Good library service for sighted students relies on a network of public, academic, and special libraries-many of which have the best collections in the world. It complements resources available in the classroom, neighbourhood bookstore, and the Internet. On the other hand, library services for students unable to read print are focused on accessible rather than best content and are dependent on small collections, a variety of agencies, and on-campus services to support course work. There are huge challenges to be overcome in order to provide print disabled students with good content comparable to that available to their sighted colleagues.

Against this background are the dynamics of the knowledge revolution that are reshaping the workplace, schools, education and the learning culture more rapidly than ever before. The world resource of information doubles every two to three years. E-mail, estimated to support over $90,000,000$ accounts, is expected to double in ten years. $80 \%$ of students and $5 \%$ of businesses surveyed in Canada said that they use the Internet for information. The job market of the next decade will be volatile, uncertain, and unsettled. It will require a workforce that is numerate, literate and more educated than previously. "In 1994, 145,000 jobs disappeared in Canada for those with high school education or less, while 42,000 new jobs were created for workers with post secondary education."' Literacy among the general population today includes technological competencies as well as the ability to read and write. At the same time the Canadian government is committed to making Canada the most connected nation in the world and to harnessing the resources of the "knowledge revolution."

Blind and print disabled students will compete for jobs and university placements in this rapidly changing working and learning environment. Currently, blind Canadians are employed in over 1,600 professions; largely the result of strong advocacy at all levels of society and increasing opportunities for education and training. Fawcett's economic portrait of disabled people in Canada indicates their labour force participation improved between 1986 and 1991, up from $48.5 \%$ to $56.3 \% .^{2}$ Sustaining and improving this achievement is dependent on acquiring competencies pertinent to the Information Age.

Among blind students literacy not only means competency with braille but a variety of special access and other technologies. Already the technological skills among print disabled people are changing. A study by the Book and Periodical Council of CNIB 
(Canadian National Institute for the Blind) Library clients revealed that $56 \%$ of those in the age range 15-65 use a computer for reading and access to information. Studies also reinforce that blind persons able to read and write braille are most likely to have higher education and to be employed. Consequently new IFLA guidelines advocate accessible braille collections throughout libraries. ${ }^{3}$ Print disabled students are not a homogeneous group. The Learning Disabilities Association of Canada estimates that $10 \%$ of the Canadian population have a lifelong learning disorder ${ }^{4}$ and the Health and Limitations Survey (HALWS) indicated over a million Canadians have a visual disability. Their needs vary depending on primary, secondary or tertiary requirements, the degree of blindness, physical handicaps, or dyslexia, which prevents them from reading print. Are the diverse current and future library service needs of these students well understood?

The Information Age with its web technology and electronic publishing is stretching the dimensions of the librarians' assumptions about the way information is organized, distributed or made accessible, and challenging them to re-invent or re-define the service. "The library without walls is a concept that is making its way throughout the library community...."s Users, whether they are blind or sighted, like both the ability to visit their libraries and/or receive service at home.

Libraries for the blind are also setting new standards for accessible books for blind people everywhere by creating a new generation of digital audio books. These libraries also recognize that current methods of building accessible collections are too slow and costly and in the next five years collection building will mean linking library data bases and information rich web sites. They are exploring standards to align publishers and libraries for faster access, resource discovery, and distribution of information.

In response to these demands for service from print disabled Canadians and the dynamics of the Information Age, the CNIB Library's national network VISUNET : CANADA is built around the premise of interconnectedness to other libraries and information sources. VISUNET : CANADA is based on three modules and supports the premise of a virtual library for Canadians unable to read print. It provides opportunities for students to be registered for service anywhere in Canada and to access current information independently or to conduct their own research.

The VISUCAT module, based on MARC standards, provides an online catalogue that can be used by students, partner libraries, and CNIB Divisions across Canada. The VISUTEXT module anticipates expansion of resources quickly, taking advantage of publisher's files and material in electronic format published on the Internet or World Wide Web or already in the CNIB Library collections. These include braille files and electronic books in the Churcher Etext Collection and other reference tools such as Encyclopaedia Britannica. Students across Canada with braille output devices or synthesized speech will be able to read these publications either as hard copy braille, refreshable braille, or as voice output. VISUNEWS is the third major module being developed to deliver current Canadian newspapers, magazines, and other publications. It will provide full text French and English newspapers, magazines, catalogues, and other documents across Canada. Phase one will introduce a full range of local and national newspapers online. Phase two will provide access using the telephone. The ability to make a digital file accessible by phone in the same time frame as newspapers are delivered to the general public is only one example of how technology is changing service opportunities.

Within Canada, the Partners Program plans to integrate the information resources and services of libraries and governments with CNIB Library resources, creating for those Canadians unable to read print both a library without walls and one place in which to look for information. Several public libraries such as those in Markham, Pickering, Regina, Edmonton, Calgary, and Cornwall are active network participants. Excellent advocacy and collaboration are also occurring at provincial levels in Alberta and British Columbia. International partnerships with the Library of Congress and the recent agreement with the National Library for the Blind (NLB) in the United Kingdom, signed on February 26, 1999, will expand content for print disabled Canadians. Both CNIB and NLB use the Geac Advance System and expect to take full advantage of the Z39.50 standard, a protocol to interconnect their online catalogues. As more libraries make their alternate format collections available on the Internet, such as the recent announcement of Louis on the Web by the American Printing House $^{6}$, the breadth and depth of accessible content will increase.

Other Consortia such as the Digital Audio Based Information System (DAISY) and the Library of Congress NLS/NISO group, whose members are libraries for the blind, represent outstanding, international collaborative efforts to produce and archive accessible content for those who cannot read print. The CNIB Library is one of five beta test sites in the world experimenting with the launching of the new generation of digital talking books. It is a member of the International Federation of Library Associations: Section of Libraries for the Blind currently involved in examining initiatives on text encoding and metadata for their impact on producing digital materials for the collection. These endeavours intend to benefit students who will be able to navigate reference works and research materials in a way that is not possible with analogue based recordings, thus providing them with the same or greater access than their sighted colleagues.

Some initiatives in Canada are contributing to these new developments. With Industry Canada's leadership, Canada's Copyright Act is one of the most progressive in the world for perceptually disabled people. It is also a leader in publisher's 
investigations into how published materials can be made accessible to print disabled Canadians. Canada is also the second country in the world to develop a special digital audio player allowing print disabled students to navigate an audio book as sighted people do.

Library service is a critical resource to the continuous learning required to compete for jobs and sustain quality of life in a civil society. Print disabled Canadians expect libraries to set new standards of access and opportunities for learning and to keep pace with change. They know that the depth of participation in the learning culture increases their prospects for employment and independence. VISUNET : CANADA envisions a service which in the next decade will be interconnected and part of the network of other types of libraries, thus creating a world resource of information in any format of choice. It is also about providing best content, setting new service standards, and the transformation to a library that is both digital and virtual, connecting users to a service where format and limited content are no longer barriers to information equity and the same information is available to everyone in the same time frame.

In the words of Robert Wedgworth, former president of IFLA: "Ideas need no passports from their place of origin, nor visas for the countries they enter. All boundaries in the world of culture and ideas are artificial and all are doomed to be dissolved." 7 In the end, the expectations set by the students themselves and the leadership provided by librarians, publishers, and advocates will define the best that is possible and remove the boundaries that limit students' access to information in the learning environment.

\section{ENDNOTES}

' David K. Foot, Boom, Bust \& Echo: How to Profit from the Coming Demographic Shift ( Toronto: Mcfarlane, Walter and Ross, 1996) 69.

${ }^{2}$ Gail Fawcett, Living with Disability in Canada: An Economic Portrait. (Ottawa: Human Resources Development Canada, 1996).

${ }^{3}$ http://www.ifla.org//VII/s31/pub/guide/htm.

${ }^{4}$ Robert Sheppard, "Battling the System," Macleans 22 June 1998: 46.

${ }^{5}$ Tim Philip, “A Library Without Walls, ” Toronto Star 2 Mar. 1998, sec. J.

6 Jeff Elliott, "American Printing House for the Blind Launches Louis on the Web," Feliciter Oct. 1998: 14-15.

${ }^{7}$ International Federation of Library Associations and Institutions, IFLA Council Report 1995-1997 (The Hague, Netherlands, 1997) 5 .

Rosemary Kavanagh is Executive Director, CNIB Library for the Blind, 1929 Bayview Avenue, Toronto, ON, Canada M4G 3E3. Phone: (416) 486-2500. 